\title{
Investigação do efeito viscosificante e estabilizante de argilas hidrofílica e hidrofóbica em fluidos emulsionados de base oleoso
}

Investigation of the viscosifying and stabilizing effect of hydrophilic and hydrophobic clays in emulsified oil-based fluids

Investigación del efecto viscosificante y estabilizador de arcillas hidrofílicas e hidrofóbicas en

fluidos a base de aceite emulsionados

Recebido: 12/02/2021 | Revisado: 20/02/2021 | Aceito: 26/02/2021 | Publicado: 04/03/2021

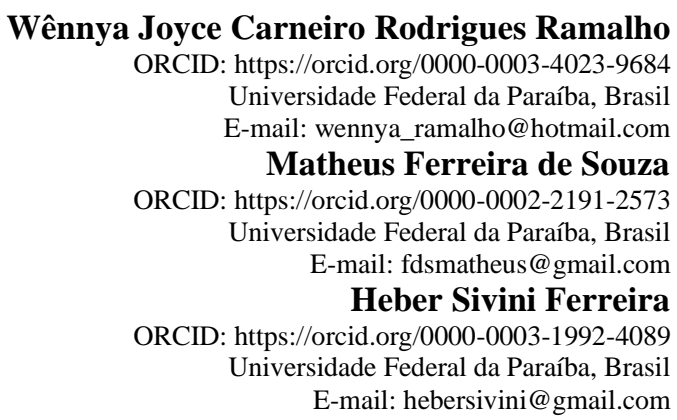

\begin{abstract}
Resumo
As bentonitas são amplamente investigadas por atuarem como agentes viscosificantes e estabilizantes de fluidos emulsionados. As propriedades dos fluidos de perfuração são extremamente importantes, para o alcance do sucesso da perfuração do poço de petróleo. Todavia, a purificação das argilas se faz necessário para promover uma melhora no comportamento reológico das dispersões. Assim como as argilas bentoníticas naturais, as argilas organofílicas obtidas a partir de argilas bentoníticas sódicas possuem uma gigantesca importância industrial devido ao seu alto grau de inchamento em água, e sais quarternários de amônio. Neste estudo, a influência do tipo de argila é investigada reologicamente em fluidos emulsionados de diferentes proporções mássicas óleo/água $(\mathrm{O} / \mathrm{W})$ : 50/50, 70/30, 80/20, 90/10 e 95/05 sob a concentração de 6000ppm. As amostras de argilas foram caracterizadas por FRX, DRX E TG/DTA. Todos os fluidos emulsionados de base oleoso foram analisados através de observações morfológicas do tipo macroscópico e reológico. As argilas bentoníticas verde-lodo purificada (hidrofílica) e verde-lodo organofílica (hidrofóbica) foram testadas como agentes viscosificantes e estabilizantes das emulsões. A partir dos resultados, foi possível verificar a composição química das argilas, sendo a argila organofílica a de maior perda ao fogo, a eficiência da intercalação do surfactante na argila verde-lodo organofílica denotada nos difratogramas de raios X, assim como, os eventos de perda de massa, onde a verde-lodo organofílica apresentou uma maior perda. Reologicamente os resultados confirmaram que somente a emulsão contendo argila verde-lodo organofílica de fração mássica 50/50 (O/W) apresentou-se estável fisicamente.
\end{abstract}

Palavras-chave: Argilas bentoníticas; Comportamento reológico; Fluidos emulsionados.

\begin{abstract}
Bentonites are extensively investigated for acting as viscosifying and stabilizing agents for emulsified fluids. The properties of drilling fluids are extremely important for the success of oil well drilling. However, the purification of clays is necessary to promote an improvement in the rheological behavior of the dispersions. Like natural bentonite clays, organophilic clays obtained from sodium bentonite clays are of enormous industrial importance due to their high degree of swelling in water, and quarternary ammonium salts. In this study, the influence of the clay type is investigated rheologically in emulsified fluids of different mass proportions oil/water $(\mathrm{O} / \mathrm{W}): 50 / 50,70 / 30,80 / 20$, $90 / 10$ and $95 / 05$ under the concentration 6000ppm. The clay samples were characterized by FRX, DRX AND TG/DTA. All oil-based emulsified fluids were analyzed through macroscopic and rheological morphological observations. Purified sludge green (hydrophilic) and organophilic sludge green (hydrophobic) clays were tested as viscosifying and stabilizing agents for emulsions. From the results, it was possible to verify the chemical composition of the clays, with the organophilic clay being the one with the greatest loss to fire, the efficiency of the surfactant intercalation in the slime-green organophilic clay shown in the X-ray diffractograms, as well as the events of mass
\end{abstract}


loss, where the organophilic slime-green showed a greater loss. Rheologically, the results confirmed that only the emulsion containing sludge-green clay of mass fraction 50/50 (O/W) was physically stable.

Keywords: Bentonite clays; Rheological behavior; Emulsified fluids.

\section{Resumen}

Las bentonitas se investigan extensamente por actuar como agentes viscosificantes y estabilizantes para fluidos emulsionados. Las propiedades de los fluidos de perforación son extremadamente importantes para el éxito de la perforación de pozos de petróleo. Sin embargo, la purificación de arcillas es necesaria para promover una mejora en el comportamiento reológico de las dispersiones. Al igual que las arcillas de bentonita natural, las arcillas organofílicas obtenidas a partir de arcillas de bentonita de sodio son de enorme importancia industrial debido a su alto grado de hinchamiento en agua y sales de amonio cuaternario. En este estudio, la influencia del tipo de arcilla se investiga reológicamente en fluidos emulsionados de diferentes proporciones de masa aceite / agua $(\mathrm{O} / \mathrm{W})$ : 50/50, 70/30, 80/20, 90/10 y 95/05 bajo el concentración 6000ppm. Las muestras de arcilla se caracterizaron por FRX, DRX Y TG / DTA. Todos los fluidos emulsionados a base de aceite se analizaron mediante observaciones morfológicas macroscópicas y reológicas. Se ensayaron arcillas verde de lodo purificado (hidrófilo) y verde de lodo organófilo (hidrófobo) como agentes viscosificantes y estabilizantes para emulsiones. A partir de los resultados, se pudo verificar la composición química de las arcillas, siendo la arcilla organofílica la que presenta mayor pérdida al fuego, la eficiencia de la intercalación del surfactante en la arcilla organofílica verde-limo mostrada en los difractogramas de rayos X , así como los eventos de pérdida de masa, donde el verde-limo organofílico mostró una mayor pérdida. Reológicamente, los resultados confirmaron que sólo la emulsión que contenía arcilla verde fangosa de fracción de masa 50/50 (O / W) era físicamente estable.

Palabras clave: Arcillas bentoníticas; Comportamiento reológico; Fluidos emulsionados.

\section{Introdução}

Partículas insolúveis ou substâncias de alto peso molecular pode estabilizar emulsões a depender de vários parâmetros como, tamanho de partícula, comportamento de umedecimento, agregação de partícula na interface, dentre outros, (Binks, Horozov, 2006). Destes parâmetros, o efeito estabilizador das partículas é realizado pela contribuição da formação da camada interfacial na qual é influenciada pelo seu comportamento de umedecimento entre as fases e pela presença de moléculas orgânicas. As partículas que são equivalentemente umedecidas em ambas as fases, aquosa e oleosa, são conhecidas por formar uma camada interfacial entre as gotículas que estabilizam as emulsões óleo/água ou água/óleo contra a coalescência (Hunter et al., 2008). A coalescência é um processo termodinamicamente favorável impulsionado pela redução da energia interfacial resultando na drenagem do filme de fase contínua entre as gotas dispersas (Ramsden, 1903).

A estabilização contra a coalescência é um dos fatores mais importantes para determinar a qualidade da emulsão. Observações macroscópicas e microscópicas estão se concentrando em explorar o efeito estabilizador da argila dependendo da composição da emulsão. As partículas coloidais melhoram o comportamento de estabilização de emulsões dependendo de suas características de superfície (Hong \& Fischer, 2016).

A dispersão ou esfoliação da argila varia em função do tamanho das partículas variando de submicrômetro a nanômetro. Além disso, o comportamento de estabilização da partícula de argila na emulsão é causado por características da superfície coloidal ou pelo fato de a viscosidade ser aumentada na fase contínua (Opawale \& Burgess, 1998). A adsorção interfacial de materiais tensoativos aumenta o módulo interfacial $\left(\mathrm{G}^{*}\right)$ dependendo a sua concentração. Todavia, para formar uma estrutura interfacial estável requer muito tempo por conta de as estruturas interfaciais continuarem mudando devido à mudança nas condições externas. Com isso, esse rearranjo estrutural é refletido no módulo interfacial $\left(\mathrm{G}^{*}\right)$. Com partículas, espera-se que o módulo interfacial seja alto o suficiente para induzir estabilidade (Larson, 1999).

Em se tratando de sistemas complexos, incluindo partículas coloidais, surfactantes ou até mesmo, sal, a reologia interfacial combinada com diversas técnicas de medição reológica foi sugerida para relacionar as diversas respostas mecânicas à formação de uma camada de adsorção interfacial (Fischer \& Erni, 2007). Isso se deve ao fato da competição que ocorre entre a interação química e física complexa durante o acúmulo da camada interfacial. A difusão rápida de surfactantes, bem como, a 
adição de sal à interface ou partículas coloidais aumenta a precipitação de partículas (Whitby, Fornasiero, Ralston, 2008) ou acumulação interfacial (Hong, Rühs, Fischer, 2015). Mesmo com tantos meios de medir as propriedades interfaciais, estamos distantes de saber o quão forte deve ser um módulo interfacial $\left(G^{*}\right)$ para fornecer estabilidade da emulsão para prevenir a coalescência induzida pela diferença de densidade entre o óleo e a água (Arditty, et al., 2004).

Neste estudo, a argila como partícula coloidal do tipo hidrofílica e hidrofóbica na concentração de 6000ppm é investigada para compreender sua atuação como um viscosificante mineral, além de sua atuação no comportamento reológico dos parâmetros viscoelásticos, módulo de armazenamento (G’) e módulo de perda ou dissipação de energia (G’) em diferentes frações mássicas óleo/água de fluidos emulsionados.

\section{Metodologia}

\subsection{Materiais}

Para as emulsões de óleo e água, óleo biodegradável (Vonder) de caráter vegetal foi usado para a fase de óleo. O óleo tem uma densidade de $1,053 \mathrm{~g} / \mathrm{cm}^{3}$. Para a fase aquosa foi utilizada água destilada. Para investigar os efeitos do tipo de argila no comportamento reológico, duas argilas de caráter hidrofílica e hidrofóbica foram usadas, sendo estas, bentonítica natural (beneficiada a partir do método de agitação mecânica por 20 minutos a uma velocidade de 19.000rpm, após isso, a solução passou por um repouso de $24 \mathrm{~h}$, sendo em seguida, submetida novamente a agitação mecânica por 5 minutos. Posteriormente, a mesma seguiu para o banho ultrassônico por 20 minutos a uma frequência de $20 \mathrm{KHz}$. Por fim, a solução foi direcionada para a centrífuga por 1 minuto a uma rotação de $700 \mathrm{rpm}$ e tempo de aceleração de 20 segundos e desaceleração de 30 segundos. Após todas essas etapas, a solução seguiu para o processo de secagem em Spray Dryer) e bentonítica organofílica (modificada em laboratório a partir da obtenção da argila purificada, sendo utilizado o tensoativo Preapagem. Inicialmente a água foi aquecida até atingir $80^{\circ} \mathrm{C}$, para em seguida, adicionar o percentual de argila na água e agitar mecanicamente por 20 minutos a 19.000rpm, após isso, a solução manteve-se em repouso por 24h. Em seguida, foi adicionado o tensoativo e submetido novamente a agitação mecânica por 20 minutos a uma rotação de $1.500 \mathrm{rpm}$. Após estes processos, as amostras seguiram para a etapa de filtração, sendo em seguida, secas em estufa a $60^{\circ} \mathrm{C}$ por $24 \mathrm{~h}$ ). A argila, consistindo em silicatos em camadas foi adquirida da Bentonit União Nordeste (BUN), oriundo do município de Boa Vista - PB. A argila bentonítica natural é compreendida por silicatos contendo íons catiônicos de sódio ( $\mathrm{Na}$ ) na superfície das plaquetas dos silicatos. Sendo renomeado neste estudo como argila verde-lodo purificada. $\mathrm{O}$ íon catiônico de sódio da superfície da argila é facilmente trocado por diversos surfactantes para controlar as propriedades da superfície. Quando é modificado organicamente com um surfactante com um hidrocarboneto de cadeia longa (C16 18), a superfície da argila tem características mais oleofílicas. A argila bentonítica modificada organicamente, denominada neste estudo como, verde-lodo organofílica. Para essa modificação utilizou o sal quaternário de amônio, comercialmente identificado como Praepagem WB® (cloreto de diestearil dimetil amônio) com $81,26 \%$ de matéria ativa, tensoativo catiônico, com peso molecular de 585,5 g/mol provido pelo fabricante CLARIANT. Espera-se que aumente o umedecimento da argila com a fase oleosa.

\subsection{Caracterização das argilas}

As argilas estudadas nesta pesquisa (verde-lodo purificada e verde-lodo organofílica) foram caracterizadas por meio dos seguintes métodos: análise química por fluorescência de raios $\mathrm{X}$ (FRX), difração de raios $\mathrm{X}$ (DRX), análise termogravimétrica (TG) e análise térmica diferencial (DTA). 


\subsubsection{Análise química por fluorescência de raios X (FRX)}

As amostras de argilas bentoníticas (verde-lodo purificada e verde-lodo organofílica) foram passadas em peneira ABNT $\mathrm{n}^{\mathrm{o}} 200(0,074 \mathrm{~mm})$ e submetidas a análise de FRX. Esta análise consiste em um espectrômetro de fluorescência de raios X que determina, semi quantitativamente, todos os óxidos presentes. Isso ocorre por meio da aplicação de raios X na superfície da amostra e pela análise dos raios X fluorescentes emitidos por cada elemento químico presente. Os raios X são gerados através do tudo com alvo de Rh. O equipamento utilizado para esta caracterização química foi o EDX 720 da Shimadzu.

\subsubsection{Difração de raios $X(D R X)$}

As argilas bentoníticas, verde-lodo purificada e verde-lodo organofílica, foram passadas em peneira ABNT $\mathrm{n}^{\circ} 200$ $(0,074 \mathrm{~mm})$ e submetidas a análise de difração de raios X em equipamento XRD-6000 da Shimadzu. As condições operacionais utilizadas foram, radiação $\mathrm{K} \alpha$ do $\mathrm{Cu}(\lambda=1,5418 \AA)$, com corrente de $30 \mathrm{~mA}$ e tensão de $40 \mathrm{kV}$, ângulo variando na faixa de $5^{\circ}$ a $60^{\circ}$, velocidade do goniômetro de $2^{\circ} / \mathrm{min}$ e passo de $0,02^{\circ}$.

\subsubsection{Análise térmica diferencial e termogravimétrica (DTA E TG)}

A análise de termogravimétrica (TG) e a termodiferencial (DTA) consistem em verificar as faixas de temperaturas onde ocorrem as perdas de massas, além de indicar as temperaturas em que ocorrem as transformações endotérmicas e exotérmicas. As análises térmicas foram obtidas através do equipamento de marca Shimadzu, modelo DTG-60 com taxa de aquecimento de $12,5^{\circ} \mathrm{C} / \mathrm{min}$ até atingir a temperatura de $1000^{\circ} \mathrm{C}$ sob atmosfera de ar com vazão de $50 \mathrm{~mL} / \mathrm{min}$.

\subsection{Preparação das emulsões}

A metodologia usada para preparação dos fluidos emulsionados consistiu em adicionar as massas das argilas equivalentes a concentração 6000ppm para uma solução de 25g das seguintes proporções mássicas (óleo/água): 50/50; 70/30; 80/20; 90/10 e 95/05 para as argilas: verde-lodo purificada e verde-lodo organofílica. Para a argila purificada a água destilada foi aquecida à $80^{\circ} \mathrm{C}$, em seguida, as dispersões foram aditivadas com a solução de $\mathrm{Na}_{2} \mathrm{CO}_{3}$. Para todos os tipos de argila, as condições de processo seguiram padrão, sendo as emulsões submetidas a agitação mecânica a uma rotação de 360rpm por um período de 20 minutos, conforme metodologia usada por Hong \& Fischer. (2016).

\subsection{Observação morfológica}

Após a preparação das emulsões, as mesmas foram fotografadas para investigar qualquer alteração macroscópica. Os vasos contendo um determinado volume de emulsão com concentração de argila de 6000ppm e proporções mássicas óleo/água: 50/50; 70/30; 80/20; 90/10 e 95/05 (O/W) com adições de argila verde-lodo purificada e organofílica foram fotografados em dois períodos de tempo distintos, após a emulsificação e com 24 h após a emulsificação para monitorar a separação de fases, conforme Hong \& Fischer. (2016).

\subsection{Ensaios reológicos}

Para as medições reológicas das emulsões, uma amostra de volume constante foi utilizada seguindo um procedimento pré-definido para minimizar o efeito do envelhecimento da emulsão. Inicialmente foram realizadas as medidas da viscosidade $(\mu)$ e da tensão de cisalhamento $(\tau)$ em função da taxa de cisalhamento $(\gamma)$ variando entre 5,1 a $1021 \mathrm{~s}^{-1}$. Em seguida, testes de varredura oscilatória foram realizados para medir o módulo de armazenamento (G' Pa) e o módulo de perda (G' Pa) em função da frequência. As medidas foram conduzidas em um reômetro TA-Instruments (Modelo AR 2000-N) com sistema 
cone-placa de geometria $(\varnothing=60 \mathrm{~mm})$. Antes do teste de varredura de frequência, teste de varredura de tensão oscilatória foi realizado para confirmar a condição viscoelástica linear da deformação. Para tanto, a tensão foi fixada em $8 \%$ para o teste de varredura de frequência. Os experimentos de varredura oscilatória foram realizados a uma amplitude $(\omega)$ de $1 \mathrm{~s}^{-1} \mathrm{em}$ função da tensão $(\gamma)$ de 0,01 a $10 \%$ sobre frequência angular $(\omega)$ de 0,01 a $1000 \mathrm{rad} / \mathrm{s}$. A temperatura foi mantida para todas as corridas em $25^{\circ} \mathrm{C}$ e todos os experimentos foram controlados por um sistema de circulação de água através de um banho termostatizado, corroborando o estudo feito por Hong \& Fischer. (2016).

\section{Resultados}

\subsection{Fluorescência de raios X (FRX)}

Na Tabela 1 estão presentes os resultados de composição química para as argilas verde-lodo purificada e verde-lodo organofílica, obtidos por fluorescência de raios X.

Tabela 1 - Composição química das argilas: verde-lodo purificada e verde-lodo organofílica.

\begin{tabular}{|c|c|c|c|c|c|c|c|c|c|c|}
\hline Argila & $\underset{\%}{\mathrm{SiO}_{2}}$ & $\begin{array}{c}\mathrm{AI}_{2} \mathbf{O}_{3} \\
\%\end{array}$ & $\begin{array}{c}\text { MgO } \\
\%\end{array}$ & $\begin{array}{c}\mathrm{Fe}_{2} \mathrm{O}_{3} \\
\%\end{array}$ & $\begin{array}{c}\mathrm{K}_{2} \mathrm{O} \\
\%\end{array}$ & $\begin{array}{c}\mathrm{CaO} \\
\%\end{array}$ & $\begin{array}{c}\mathrm{TiO}_{2} \\
\%\end{array}$ & $\begin{array}{c}\mathrm{BaO} \\
\%\end{array}$ & $\begin{array}{c}\text { Outros } \\
\text { Óxidos } \\
\%\end{array}$ & $\begin{array}{c}\text { PF } \\
\%\end{array}$ \\
\hline Purificada & 48,54 & 26,87 & 6,34 & 6,21 & 0,86 & 0,81 & 0,77 & 0,23 & 0,12 & 9,23 \\
\hline Organofílica & 41,21 & 22,45 & 5,09 & 5,38 & 0,72 & 0,49 & 0,64 & 0,18 & 0,11 & 23,72 \\
\hline
\end{tabular}

Fonte: Autores.

Analisando os resultados obtidos a partir da Tabela 1, constata-se que o teor de $\mathrm{SiO}_{2}$ e o teor de $\mathrm{Al}_{2} \mathrm{O}_{3}$ foram similares para os dois tipos de argila, sendo ligeiramente superior para a argila verde-lodo purificada, evidenciando uma maior fração de argila. Para o teor de $\mathrm{MgO}$, a argila purificada apresentou o teor mais elevado, demonstrando com mais efetividade a presença do magnésio nessa amostra. Os teores de $\mathrm{Fe}_{2} \mathrm{O}_{3}$ e $\mathrm{K}_{2} \mathrm{O}$, apresentaram-se semelhantes para ambas as argilas. Para os teores de $\mathrm{CaO}$, nota-se que a purificada exibiu o teor mais elevado corroborando a origem geológica policatiônica da argila. Os teores de $\mathrm{TiO}_{2}$ e $\mathrm{BaO}$ para a argila verde-lodo purificada e verde-lodo organofílica foram similares novamente. Outros óxidos apresentaram-se para todas as argilas, porém em baixos teores. A perda ao fogo apresentou teores significativamente distintos, sendo efetivamente maior para a argila verde-lodo organofílica.

É fato a observação de que todos os tipos de argilas apresentaram composição química típica das argilas bentoníticas (Souza Santos,1992; Amorim, 2003; Campos, 2007).

\subsection{Difração de raios X (DRX)}

Na Figura 1 estão apresentados os resultados de difração de raios X das argilas: (a) verde-lodo purificada e (b) verdelodo organofílica. 
Figura 1 - Difratogramas das argilas verde-lodo purificada (a) e verde-lodo organofílica (b).

(a)

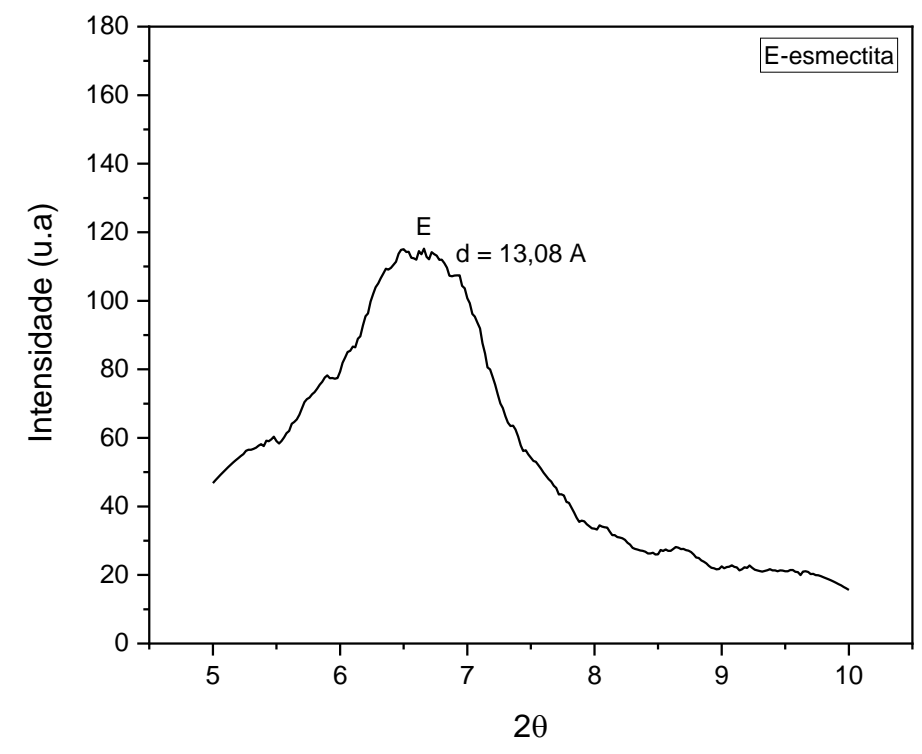

(b)

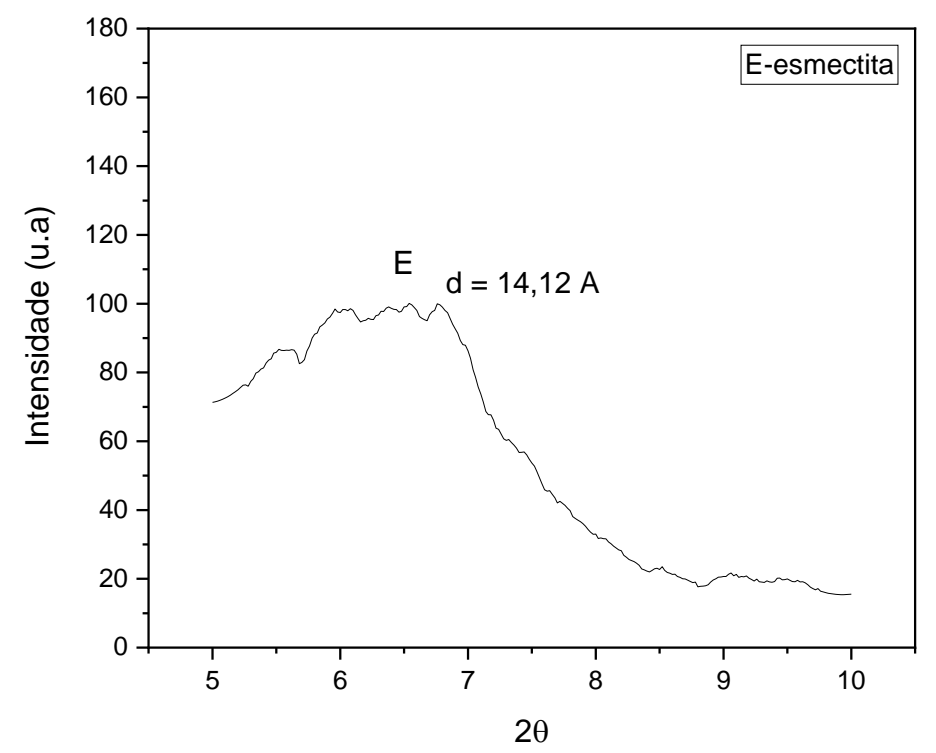

Fonte: Autores.

Sucintamente, os difratogramas da Figura 1 evidenciaram a constante presença do argilomineral esmectítico para todas

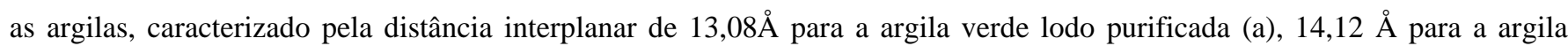
verde-lodo organofílica (b).

O aumento da distância interplanar é refletido no difratograma pela redução do ângulo de difração, e pode ser visualizada na forma do deslocamento dos picos de DRX para ângulos menores. Este deslocamento foi observado no difratograma da verde-lodo organofílica, mostrada na Figura 1(b), sendo levemente deslocado para esquerda, evidenciando que houve efetivamente a intercalação do sal orgânico entre os espaços interlamelares de argila. Resultados similares foram encontrados por Barbosa et al. (2006) e Brasileiro (2018). 


\subsection{Análise térmica diferencial (DTA) E Termogravimetria (TG)}

As Figuras 2 e 3, apresentam as curvas referentes as análises termogravimétricas e térmicas diferenciais das argilas bentoníticas estudadas nesta pesquisa.

Figura 2 - Análise Térmica da argila verde-lodo purificada.

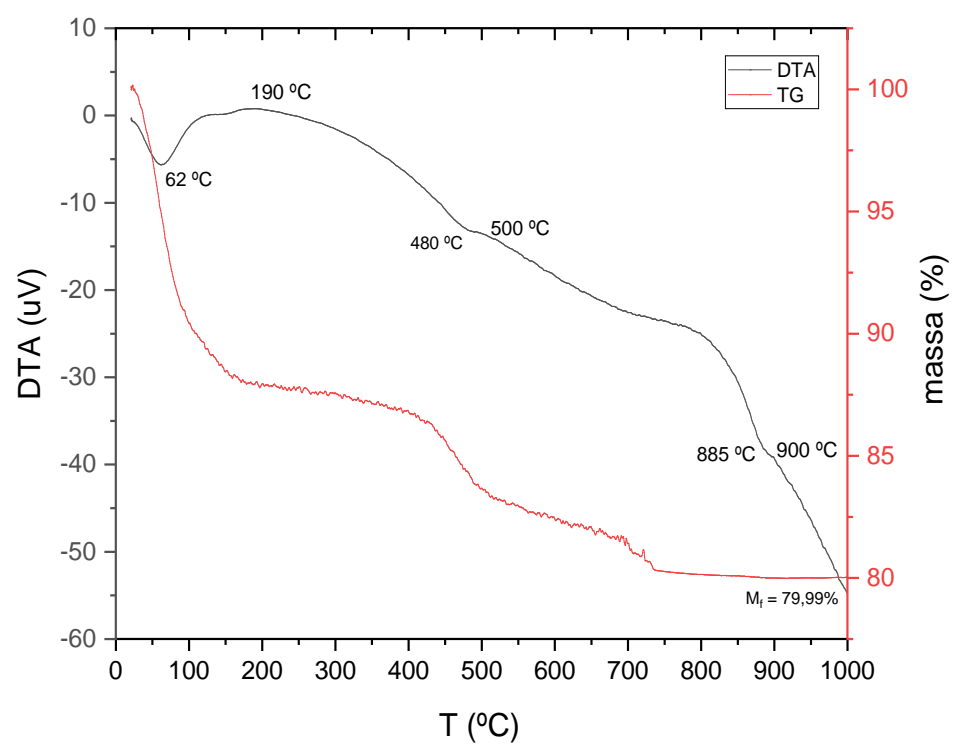

Fonte: Autores.

Figura 3 - Análise Térmica da argila verde-lodo organofílica.

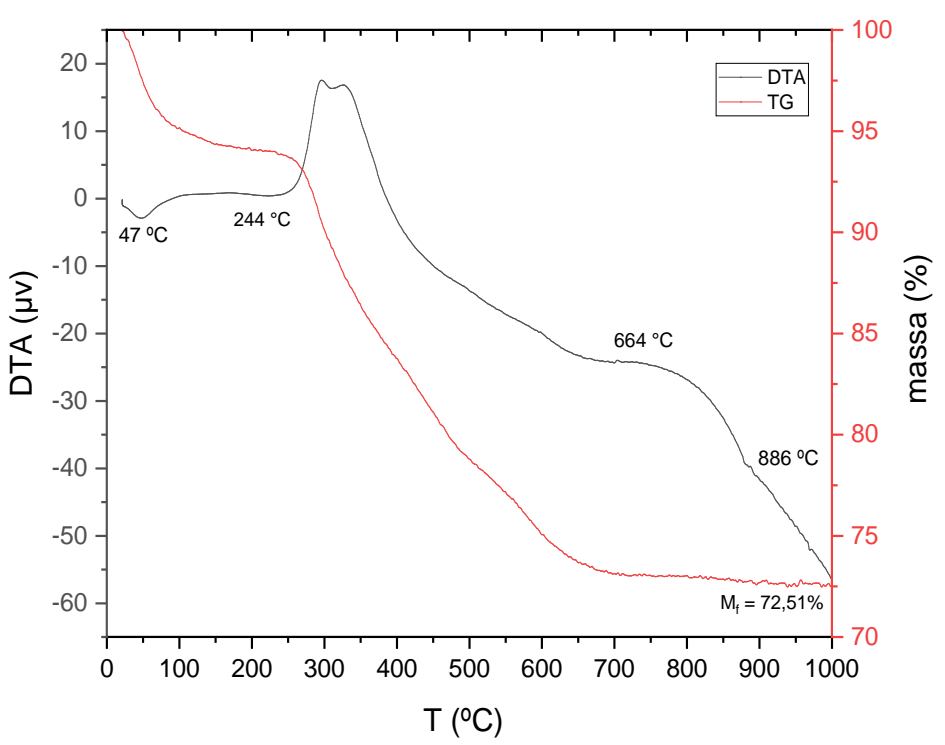

Fonte: Autores. 
Analisando as curvas de DTA da argila verde-lodo purificada referente a Figura 2, observa-se um pico endotérmico em torno de $62{ }^{\circ} \mathrm{C}$ característico da presença de água livre. O pico em $190{ }^{\circ} \mathrm{C}$ refere-se à perda de matéria orgânica. $\mathrm{O}$ evento em 480-500 ${ }^{\circ} \mathrm{C}$ corresponde a desidroxilação. Em $885-900{ }^{\circ} \mathrm{C}$ corresponde a destruição do retículo cristalino. Além disso, observa-se que a massa final no término do ensaio termogravimétrico foi de 79,99\% da massa inicial, corroborando a uma perda de massa de 20,01\%. Resultados semelhantes foram encontrados por Sousa (2010) e Brasileiro (2018).

Avaliando a Figura 3, referente a argila verde-lodo organofílica, nota-se a presença de um pico endotérmico em torno de $47{ }^{\circ} \mathrm{C}$ correspondente a presença de água livre. O evento em $244-664{ }^{\circ} \mathrm{C}$ é alusivo à decomposição do tensor orgânico e a desidroxilação. Em $880{ }^{\circ} \mathrm{C}$ tem-se a destruição do reticulado. É evidente constatar que a argila verde-lodo organofílica apresentou uma massa final equivalente a $72,51 \%$, o que corresponde a uma perda de massa de $28,88 \%$ evidenciando uma incorporação de cerca de 30\% de tensoativo. Paiva, Morales e Valenzuela (2008), Sousa (2010) e Brasileiro (2018) analisando argilas bentoníticas sintetizadas a partir de sais quaternários de amônio obtiveram resultados semelhantes a este.

\subsection{Observação morfológica}

A falta de miscibilidade termodinâmica entre o óleo e a água, conduz consequentemente uma emulsão de óleo em água para a separação de fases, caso não haja uma energia de mistura externa. Entretanto, como o óleo utilizado neste estudo se trata de um óleo biodegradável de base vegetal, sendo miscível quando misturado com a água, as emulsões não apresentaram separação de fases após a emulsificação.

Para prevenir a coalescência, moléculas anfifílicas são normalmente adicionadas para induzir uma repulsão estérica ou eletrostática eficaz entre as gotas. Além dessas moléculas, partículas sólidas são adicionadas para formar uma camada interfacial para promover a estabilização da emulsão. A camada interfacial gerada por partículas sólidas pode ser mais rígida do que as formadas pelas moléculas anfifílicas. Para formação de uma interface tão rígida, as partículas de argila devem estar localizadas na interface e manter sua localização durante a emulsificação (Kralchevsky et al.,2005, Pawar et al., 2011).

A Figura 4 compara imagens macroscópicas de fluidos emulsionados em diferentes frações mássicas $(\mathrm{O} / \mathrm{W})$ contendo uma concentração de argila de 6000ppm após 30 minutos da emulsificação. Para este sistema de emulsão de óleo/água, cada emulsão é misturada com argila de diferentes características de superfície com a finalidade de investigar o efeito das argilas como viscosificantes e estabilizantes das emulsões. 
Figura 4 - Observação macroscópica das argilas na concentração de 6000ppm.

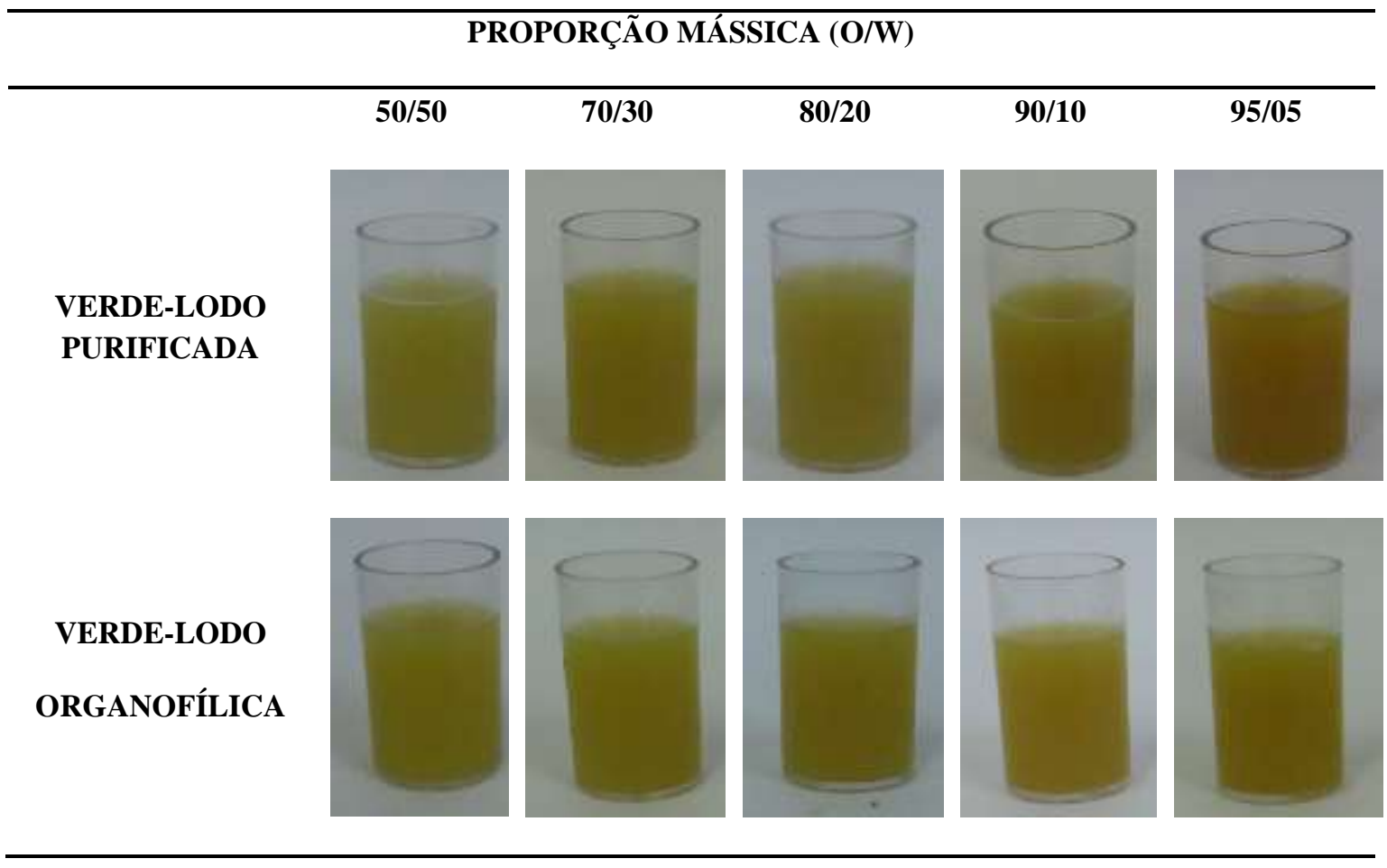

Fonte: Autores.

Através dessa observação macroscópica mostrada na Figura 4, nota-se que realmente não há separação de fases óleo em água, correspondendo dessa forma, a propriedade de miscibilidade do óleo para com a água. Em algumas horas após a emulsificação, as emulsões exibiram sedimentação das partículas de argila (não mostrado aqui). Nota-se ainda a ausência da formação de creme na parte superior da argila verde-lodo purificada, como observado por Jeon \& Hong (2014).

Os diferentes comportamentos de estabilização das argilas foram estudados por Kim et al. (2013), sendo possível perceber que as argilas mostraram-se em diferentes localizações interfaciais, a depender do seu comportamento de umedecimento entre o óleo e a água. Um outro estudo realizado por Hong, et al., (2019) mostrou que dependendo do tipo de argila, a mesma reduz a tensão interfacial de forma diferente.

\subsection{Parâmetros viscoelásticos}

Parâmetros viscoelásticos como o módulo de armazenamento ou de rigidez dinâmica (G') e o módulo de cisalhamento ou de perda (G”) foram estudados ao longo desta pesquisa visando avaliar a parcela de energia proveniente da tensão aplicada, que é temporariamente armazenada durante o teste, mas que pode ser recuperada, posteriormente, além de avaliar a parcela de energia que foi utilizada para iniciar o escoamento do fluido (Machado, 2002). Para obter esses parâmetros, realizou-se uma série de medições preliminares com o objetivo de identificar a região viscoelástica linear. A partir desta região, uma amplitude de deformação constante foi selecionada, sendo para esta pesquisa $8 \%$, para uma série subsequente de medições em que a amplitude da tensão foi obtida em função da mudança da frequência oscilatória.

É reconhecido que o comportamento viscoelástico, somado ao comportamento de cisalhamento e a observação de uma tensão de escoamento são parâmetros reológicos que indicam a presença de uma estrutura de rede elástica fraca. No caso das emulsões, o comportamento viscoelástico ocorre devido o surgimento de uma rede criada entre as gotículas de fase dispersa. Nos casos em que as partículas coloidais são usadas como agentes estabilizadores, parece que a adesão de gotículas da fase 
dispersa pode surgir através do compartilhamento das partículas coloidais, e assim, fornecer um importante mecanismo de estabilização retardando a coalescência (Stancik \& Fuller, 2004).

As Figuras 5 e 6 comparam a viscoelasticidade linear dos fluidos emulsionados para argilas com propriedades de superfície diferentes: verde-lodo purificada e verde-lodo organofílica em proporção mássica de óleo/água: 50/50, 70/30, 80/20, 90/10 e 95/05 (O/W) e concentração de argila 6000ppm.

Figura 5 - Respostas dos parâmetros viscoelásticos G' e G" para a concentração de 6000ppm da argila verde-lodo purificada.
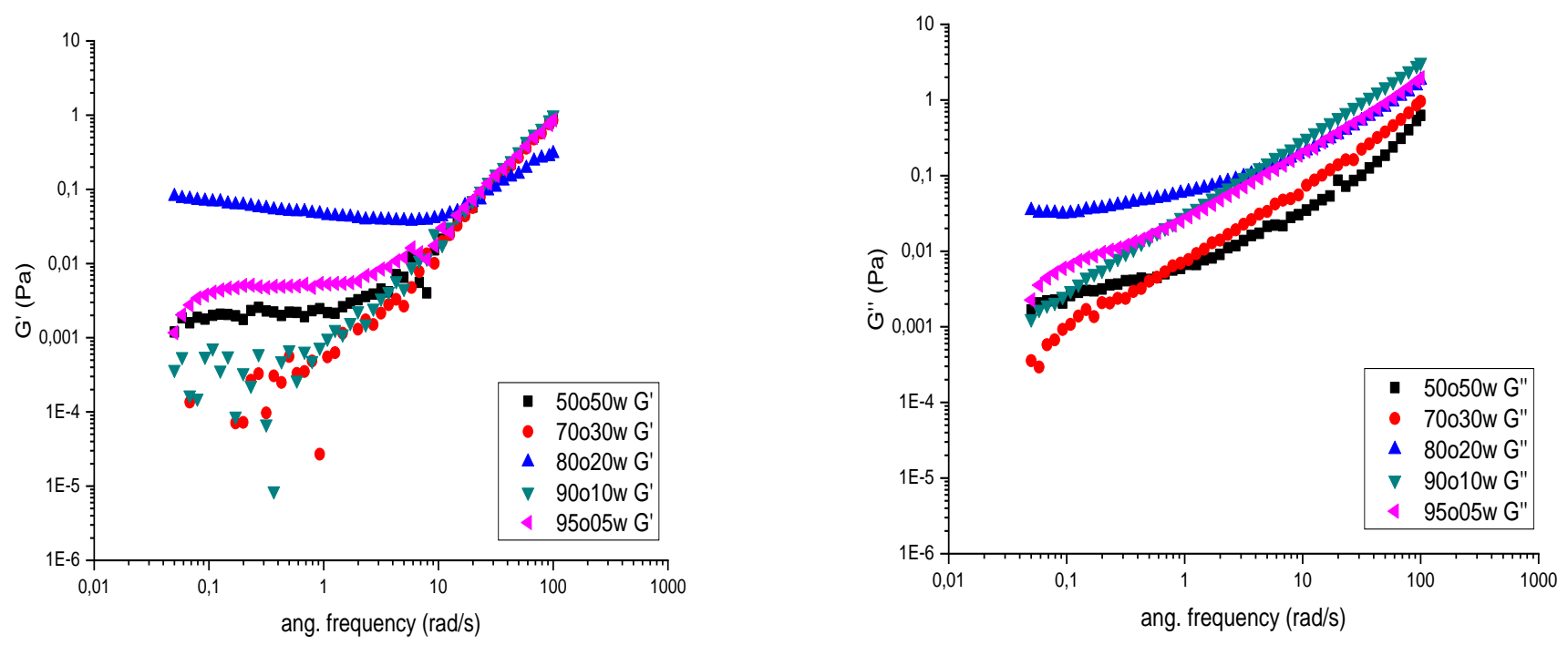

Fonte: Autores. 
Figura 6 - Respostas dos parâmetros viscoelásticos G' e G" para a concentração de 6000ppm da argila verde-lodo organofílica.

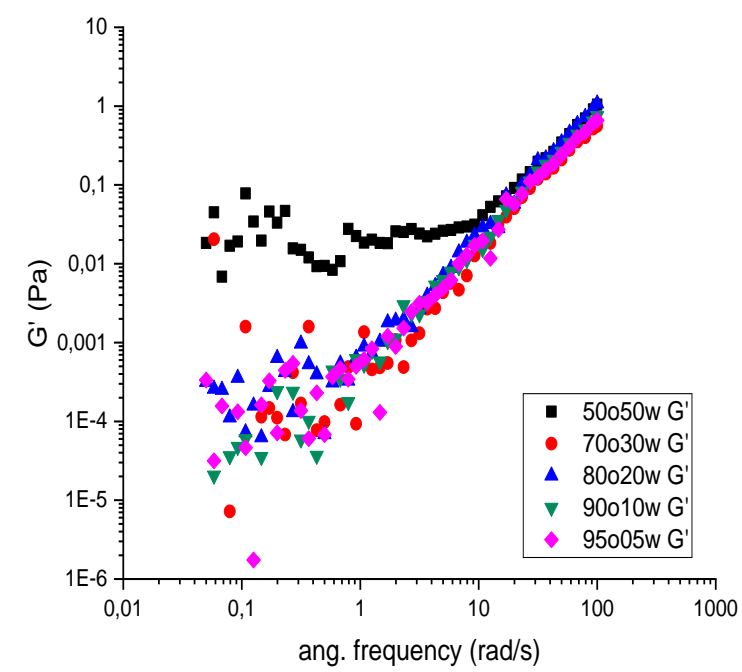

Fonte: Autores.

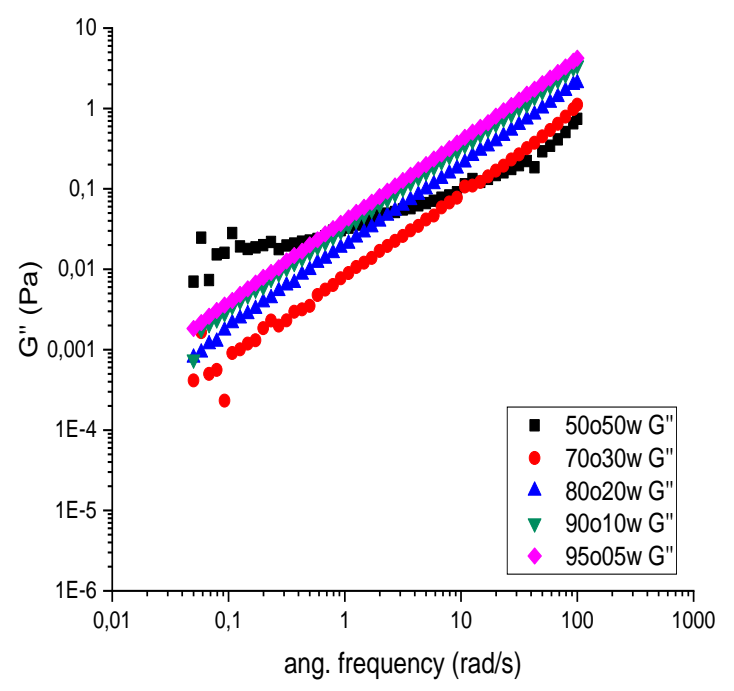

Analisando as Figuras de modo geral, é perceptível a existência de uma relação linear entre os módulos de armazenamento $\left(G^{\prime}\right)$ e perda $\left(G^{\prime \prime}\right)$ para com a frequência angular $(\omega)$, pois para todas as proporções de razão óleo/água $(\mathrm{O} / \mathrm{W})$ as emulsões tiveram seus módulos G' e G” acrescidos, conforme o aumento da frequência.

As proporções 50/50, 80/20 e 95/05 (O/W) com a argila verde-lodo purificada, evidenciadas na Figura 5, exibiram um comportamento de platô do módulo de armazenamento $\left(G^{\prime}\right)$ sobre a região de baixa frequência, isso sugere-se a influência da região interfacial intensificada de $\mathrm{O} / \mathrm{W}$ com a partícula. Sabe-se que a propriedade interfacial da região aprimorada desempenha um papel como resistência contra a deformação que aumenta o módulo de armazenamento da emulsão (Larson 1999).

Por outro lado, nota-se na Figura 6, que para baixas frequências mantém um comportamento ilógico para as proporções, porém, é perceptível que a proporção 50/50 (O/W) apresentou um maior caráter elástico, ou seja, a quantidade de energia armazenada $\left(G^{\prime}\right)$ é superior as demais proporções. Todavia, para frequências mais elevadas, especificamente a partir de 10 $\mathrm{rad} / \mathrm{s}$, todas as proporções se sobreporam exibindo semelhantemente a mesma energia de armazenamento (G'). Além disso, observa-se que a emulsão de proporção 50/50 (O/W) aumentou significativamente o módulo de armazenamento.

Como o módulo de perda ou dissipação de energia ( $\left.G^{\prime \prime}\right)$ é maior do que o módulo de armazenamento $\left(G^{\prime}\right),\left(G^{\prime}>G^{\prime}\right)$ para todas as proporções mássicas, e G’ e G” são dependentes da frequência, isso implica que estas emulsões não possuem estabilidade física, sendo, portanto, denominadas de soluções diluídas (Ross-Murphy, 1995).

Quando uma emulsão é fisicamente estável é criado um sistema de rede elástico de gel forte (Tadros, 2004). Portanto, estas proporções de óleo/água estudadas formaram emulsões instáveis, mostrando um comportamento predominantemente viscoso caracterizando o sistema como gel fraco (Torres et al., 2007).

Em função de todos os resultados obtidos nesta pesquisa, as caracterizações evidenciaram que de fato, as amostras analisadas pertencem fielmente ao grupo das esmectitas, e por este motivo, são propicias para aplicações em fluidos de perfuração. Através dos parâmetros viscoelásticos ( $G^{\prime}$ e $\left.G^{\prime}\right)$ tornou-se possível constatar que a argila verde-lodo purificada 
apresentou uma região interfacial intensificada para três proporções $(\mathrm{O} / \mathrm{W})$, sendo assim, mais resistentes a sofrer o processo de coalescência, como corrobora, o aumento do módulo de armazenamento ( $\left.G^{\prime}\right)$ dos fluidos emulsionados. Para a argila verdelodo organofílica, somente a emulsão de proporção mássica 50/50 (O/W) exibiu um maior módulo de armazenamento (G') evidenciando um caráter elástico. Dessa forma, todas as emulsões, com distinção da proporção 50/50 (O/W) da argila verdelodo organofílica, são caracterizadas como sendo emulsões instáveis, uma vez que, G” $>$ G’ e são totalmente dependentes da frequência.

\section{Conclusões}

Este estudo investigou o comportamento reológico de duas argilas apresentando diferentes características de superfície e propriedades umectantes. As argilas mostraram diferentes comportamentos de estabilização nos fluidos emulsionados devido apresentarem diferentes localizações. Para a argila verde-lodo purificada (hidrofílica), as emulsões 50/50, 80/20 e 95/05 (O/W) exibiram uma ligeira resistência ao escoamento em baixas frequências, já utilizando a argila verde-lodo organofílica (hidrofóbica) apenas a emulsão de proporção 50/50 (O/W) exibiu um caráter mais elástico, apresentando um maior módulo de armazenamento (G'). Ainda através dos parâmetros viscoelásticos, foi perceptível que para todas as proporções, com exceção da 50/50 (O/W) com argila hidrofóbica, os fluidos emulsionados apresentaram suavemente $G$ ' $>\mathrm{G}$ ', sendo estes dependentes da frequência angular $(\omega)$ caracterizando-se em emulsões instáveis, com pouca ou nenhuma estrutura de rede, sendo, portanto, denominadas de soluções diluídas.

Para o progresso deste trabalho, algumas sugestões são de grande relevância, dentre elas, a mistura de uma argila hidrofílica com uma argila hidrofóbica e o uso de tensoativo e/ou co-tensoativo para medir as propriedades reológicas das emulsões, de modo a avaliar suas propriedades, bem como, o efeito causado no comportamento reológico.

\section{Referências}

Amorim, L. V.(2003). Melhoria, proteção e recuperação da reologia de fluidos hidroargilosos para uso na perfuração de poços de petróleo, Tese de Doutorado apresentada ao Curso de Engenharia de Processos/CCT/UFCG, Dezembro de 2003.

Arditty, S., Schmitt, V., Giermanska-Kahn, J. \& Leal-Calderon, F. (2004). Materials based on solid-stabilized emulsions, Colloid Int. Sci. 275 (2004) 659-664.

Barbosa, R., Araújo, E. M., de Oliveira, A. D. \& de Melo, T. J. A. (2006). Efeito de sais quaternários de amônio na organofilização de uma argila Bentonita nacional (Efect of quaternary ammonium salts on the organophilization of. Cerâmica, 52, 264- 268.

Binks, B. P., \& Horozov, T. S. (2006). Colloidal particles at liquid interfaces. Cambridge University.

Brasileiro, C. T. (2018). Otimização da ativação com carbonato de lítio (Li2CO3) através de diferentes métodos na reologia da argila verde-lodo purificada para fluidos base água e base óleo. 2018. 111 f, Dissertação (Mestrado em Ciência e Engenharia de Materiais) - Universidade Federal da Paraíba, João Pessoa.

Campos, L. F. A. (2007). Composições de argilas bentoníticas para utilização em fluidos de perfuração de poços de petróleo, Tese de Doutorado apresentada ao Curso de Engenharia de Processos/CCT/UFCG, 2007.

Fischer, P., \& Erni, P. (2007). Emulsion drops in external flow fields - The role of liquid interfaces, Curr. Opin. Colloid Interface Sci. 12 (2007) 196-205.

Hong, J. S., \& Fischer, P. (2016). Bulk and interfacial rheology of emulsions stabilized with clay particles. colloids and surfaces a: physicochemical and engineering aspects, 508, 316-326. https://doi.org/10.1016/j.colsurfa.2016.08.040.

Hong, J. S., Kong, H. J., Hyun, K., Bergfreund, J., Fischer, P. \& Ahn, K. H. (2019). Rheological analysis of oil-water emulsions stabilized with clay particles by LAOS and interfacial shear moduli measurements. Rheologica Acta, 58(8), 453-466. https://doi.org/10.1007/s00397-019-01144-0

Hong, J. S., Rühs, P. A. \& Fischer, P. (2015). Localization of clay particles at the oil-water interface in the presence of surfactants, Rheol. Acta 54 (2015) 725734.

Hunter, T. N., Pugh, R. J., Franks, G. V. \& Jameson, G. J. (2008). The role of particles in stabilising foams and emulsions. Adv Colloid Interf Sci 137:57-81.

Jeon, T. Y., \& Hong, J. S. (2014). Stabilization of O/W emulsion with hydrophilic/hydrophobic clayparticles. Colloid and Polymer Science, 292(11), 29392947. https://doi.org/10.1007/s00396-014-3353-2 
Research, Society and Development, v. 10, n. 3, e3910312927, 2021

(CC BY 4.0) | ISSN 2525-3409 | DOI: http://dx.doi.org/10.33448/rsd-v10i3.12927

Kralchevsky, P. A., Ivanov, I. B., Ananthapadmanabhan, K. P. \& Lips, A. (2005). On the thermodynamics of particle-stabilized emulsions: curvature effects and catastrophic phase inversion. Langmuir 21:50-63.

Larson, R. G. (1999). The structure and rheology of complex fluids. Oxford University.

Machado, J. C. V. (2002). Reologia e escoamento de fluidos: ênfase na indústria do petróleo. Editora Interciência

Opawale, F. O. \& Burgess D. J. (1998). Influence of interfacial properties of lipophilic surfactants on water-in-oil emulsion stability, J. Colloid Interface Sci. 197 (1998) 142-150.

Paiva, L., Morales, A. R. \& Valenzuela-Diaz, F. R. (2008). Organoclays: Properties, preparation and applications. Applied Clay Science, Elsevier B.V., 42(12), 8-24.

Pawar, A. B., Caggioni, M., Ergun, R., Hartel, R. W. \& Spicer, P. T. (2011). Arrested coalescence of viscoelastic droplets with internal microstructure. Soft Matter 7:7710

Ramsden, W. (1903). Separation of solids in the surface-layers of solutions and 'suspensions' (observations on surface-membranes, bubbles, emulsions, and mechanical coagulation). Proc R Soc Lond 72:156-164

Ross, C. S. \& Shannon, E. V. (1926). The minerals of bentonite and related clays and their physical properties. Journal of the American Ceramic Society, 9: 7779 .

Stancik, E. J. \& Fuller, G. G. (2004). Connect the drops: Using solids as adhesives for liquids. Langmuir, 20(12), 4805-4808. https://doi.org/10.1021/la049778e.

Sousa, F. K. A. (2010). Estudo de composições de argilas organofílicas para fluidos de perfuração de poços de petróleo em águas ultraprofundas, Tese de Doutorado. Programa de Pós-Graduação em Ciência e Engenharia de Materiais. Universidade Federal de Campina Grande - UFCG, 2010.

Souza Santos, P. (1992). Tecnologia de argilas, Ed. Edgard Blücher.

Tadros, T. (2004). Application of rheology for assessment and prediction of the long-term physical stability of emulsions. In Advances in Colloid and Interface Science (Vols. 108-109). https://doi.org/10.1016/j.cis.2003.10.025.

Torres, L. G., Iturbe, R., Snowden, M. J., Chowdhry, B. Z. \& Leharne, S. A. (2007). Preparation of o/w emulsions stabilized by solid particles and their characterization by oscillatory rheology. Colloids and Surfaces A: Physicochemical and Engineering Aspects, 302(1-3), 439-448. https://doi.org/10.1016/j.colsurfa.2007.03.009.

Whitby, C. P., Fornasiero, D. \& Ralston, J. (2008). Effect of oil soluble surfactant in emulsions stabilized by clay particles, J. Colloid Interface. Sci. 323 (2008) 410-419. 